\title{
Business Networking as a Tool of the Information and Knowledge Management of the Owners of Small and Middle Enterprises - Case of Study
}

\section{Lucie NOVOTNA}

University of Hradec Kralove, Hradec Kralove, Czech Republic, lucie@vzdelavacka

\begin{abstract}
This article sums up the results of my research and qualitative expert interviews with owners of small and medium-sized enterprises active in the Czech Republic. The qualitative sample of these interviews includes respondents through the whole field spectrum of entrepreneurial activities, which are enabled by the Trade Licencing Office of the Czech Republic and are classified in the CZ-NACE database. This research took place during the world COVID-19 pandemic when the strictest measures were adopted in the Czech Republic concerning grouping, entrepreneurship, and movement. The research also sums up the short-term and the long-term change ratio of offline and online networking and information tools, which occurred in individual companies because of these measurements. The research shows an interconnection of the management discipline of information and knowledge management and networking as tools of marketing, HR, business, and building of client-supplier networks, which create sources for companies, enhance their competitiveness and lower the risk of company closures in the time of economic boom as well as crisis.
\end{abstract}

Keywords: business networking; information and knowledge management; expert interview; COVID-19; small and middle-sized entrepreneurs

JEL Classification: D01; M21; M31

\section{Introduction}

Business Networking is a strategic behaviour of a company, which purposefully and regularly wins new contacts for its development and keeps existing contacts over a long period. Business networks are complex networks of reciprocally dependent exchange relations, in which companies and individual managers act. They consist of various involved persons, complicated interactions, and organisational structures, and processes of resource transformations (Henneberg et al., 2010). Russian and Finnish authors claim that an enterprise is not an island and is very dependent on its relationships. Relationships influence the given enterprise's success as well as failure. Relationships exist in dyads and as such, they form networks. (Ivanova-Gongne \& Torkkeli, 2018). The contact sphere of a company is generally divided into client base, supplier contact chain, and partner companies or organisations. All these contacts create the company's environment and build a contact network with ties, which can have different depth and worth for the given company. Although companies act as units, when taking part in business networking activities, the 
connections and relationships are based on the individual company employees. Ordinarily, it is the owner of a company, who performs business networking activities, as he/she has the greatest range of engagement and motivation for the growth and development of his/her company. These activities can be fulfilled by managers, who are appointed by the company owners, this model is seen within bigger or corporate businesses. In the case of the companies from the SME category, the owners are mostly the ones, who create networking activities and thus build local networks (Kubberød et al., 2019). Smaller companies do business networking often intuitively, they do not specifically create tools and conditions for measuring the benefits of these activities. Bigger companies (concerning their return, number of employees, length on the market, the volume of knowledge, and experience) often assign managers, who have clearly set goals, which they want to reach against the investment into such activities. Business networking, whether online or offline, is time-consuming. To activate a network of contacts for a company and get it ready to continuously deliver contracts, first-rate suppliers, information, knowledge, and further education, the company must keep in touch with individual contacts in its network. It is vital to keep positive reciprocal relations (interest in the needs of customers, suppliers, and business partners). "Successful building of networks among the players in any single relationship depends on their ability to efficiently create networks in other relationships. Networks are diverse and unique. Each participant sets his/her goals according to a unique manner. A business network is not a market. A business network is an arena, in which interdependent actors interconnect uniquely, and the business network adapts a wide variety of practices and structures within and among actors. All business players will be most probably willing to control their interactions with others, however, none of the business players has resources, skills, or knowledge to manage this perfectly." The practice of building new business networks remains a relatively unresearched field (Ford \& Mouzas, 2013).

Business networking is a specific name for the better-known expression: networking. A Bangladeshi study in the field of the clothing industry, focusing on relationships in networks, innovativeness of business processes, and performance of export confirms the direct impact of networking on innovations. "The form of building networks (personal, intercompany) has a direct impact on business process innovations and the export performance" (Faroque et al., 2017). Networking or the creation of active networks is not only a specific skill for an entrepreneurial environment, networking is generally used in IT, HR, and also in many sport and leisure activities. We can say that a family also builds a network of contacts. An interesting part of my research are the connections and relations between networking and information and knowledge management as disciplines of modern science and management practice. Networking simplifies gaining knowledge, skills, and resources vital for the company's development and its survival, which would otherwise be difficult to obtain. Small and middle enterprises profit the most from creating networks, as they often lack sufficient resources and knowledge to deal with the environment, in which they operate. As small and middle enterprises often do not have sufficient in-house knowledge and resources, it is important to actively build and maintain proper networks to effectively gain needed resources" (Schoonjans et al., 2011). 
Information and knowledge management has a broad spectrum of characteristics and definitions One of the first authors, who focused on information and knowledge management in its current form was Mihály Polanyi. He talks about production factors as production limitations and he sees productivity and innovation in the man's ability to apply knowledge in the production process, he introduces the expression Knowledge worker (Tallinn University, 2010). “Knowledge management focuses on systematic approaches to searching, understanding, and using knowledge to create values" (Bureš, 2007). "Knowledge management means giving the right knowledge to the right people at the right time to enable them to make the best decisions" (Petrash, 1996). "Knowledge management is a process of identification, growth and efficient usage of existing in-house knowledge to reach the company's goals, and simultaneously build organisation culture, which enables further knowledge creation" (Susanssee, 2002). The basis of the KIM is the general scheme of hierarchy and creation of data, information, knowledge in pursuance of understanding and relations. A detailed explanation can be seen in Table 1 and Figure 1.

Table 1. Data, Information, Knowledge, Understanding, Wisdom. Adapted from and adjusted according to (Bureš, 2007).

\begin{tabular}{|l|l|}
\hline Concepts & Explanation \\
\hline Data & Symbols \\
\hline Information & Data including answers to the questions: who? what? where? when? \\
\hline Knowledge & The ability to use information in order to answer the question: how? \\
\hline Understanding & The ability to answer the question: why? \\
\hline Wisdom & $\begin{array}{l}\text { To ask oneself questions, which are not easy to answer, to see the good } \\
\text { and the evil, morality, principles }\end{array}$ \\
\hline
\end{tabular}

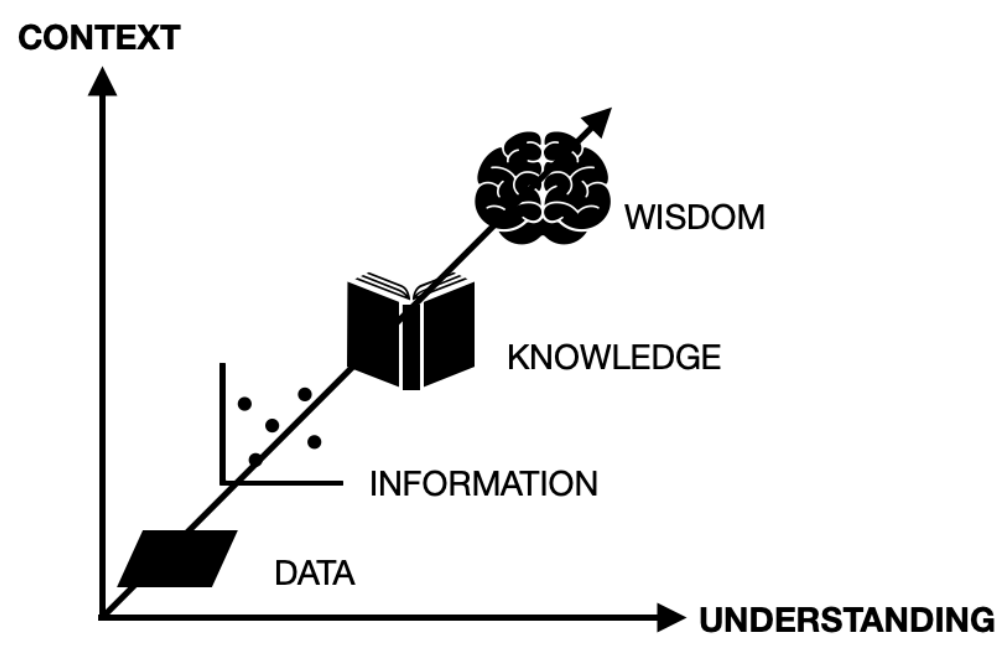

Figure 1. Data, information, knowledge, wisdom.

\section{Methodology}

The method of systematic research as per Prisma standards was used in my research (Prisma, 2021). Another method was expert interviewing via the online platform ZOOM (Prisma, 2021). An oral agreement has been given to all the expert interviews and the sound 
form (Mp3), as well as the video form (Mp4), were recorded. The respondents are owners of small and middle-sized enterprises, who conduct business in various industries in the Czech Republic. The qualitative expert interview contains 16 interviews. In an expert interview, there are 9 question sets, 7 sets include on average 6 sub-questions, the 8th set examined the awareness of claims about networking and information and knowledge management. The 9th set served for the respondents' suggestions.

\section{Results}

Each expert interview lasted on average 80 minutes and the total net time of the interviews took over 1,280 minutes, i.e. 21 hours of net time, which were recorded on sound and video footage. The following results emerged from the expert interviews.

- Set of general questions,

- Information and knowledge management set,

- Networking basics set,

- Working with contacts,

- Offline networking,

- Online networking,

- Changes in tools in the time of COVID-19 pandemic,

- Set of YES/NO questions, claims,

- Additional information.

The set of general questions brings an overview about respondents of the qualitative research. $38 \%$ of the respondents (owners of small and middle enterprises) are own-account workers, $63 \%$ of the respondents in my research are owners of Juridical persons. $75 \%$ of the respondents have a university degree and $25 \%$ have secondary or vocational education. The respondents conduct business in the field of advocacy, IT technologies, the tourist industry, education and consulting, handcraft, finance, event agency, civil engineering, and accounting. $44 \%$ of the respondents have been active in their field of business for 5-10 years, $13 \%$ of respondents $10-15$ years and $44 \%$ of respondents have been active for more than 15 years. $44 \%$ of the respondents own a company with up to 5 employees, $6 \%$ of the respondents own a company with up to 20 employees, $6 \%$ up to 50 employees, and $44 \%$ of the companies in my research employ over 50 people. $62 \%$ of the respondents have a given vision and company goals in writing and $37 \%$ of the respondents have a vision and company goal given verbally or none at all (19\%).

The Information and knowledge management question set brought the following results. $44 \%$ of the respondents are aware of the core of the information and knowledge management and $56 \%$ of the respondents heard about this discipline for the very first time. $81 \%$ of the respondents were able to hierarchically sort the expressions - data, information, knowledge, wisdom. The most frequently confused expressions were data and information. An interesting trend in the research showed the non-existing connection between networking and information and knowledge management. The respondents generally gain information and knowledge from their own company experience with their clients, a smaller group gets 
information from the internet, social networks, also from professional website and conferences, a smaller group from podcasts and books (e-book as well as print books). Only one of the respondents has a subscription for scientific articles from Oxford University, which are offered to the public against payment. None of the respondents stated to get information and knowledge dominantly from networking activities, after an additional question if they acknowledge networking as a tool to obtain information and knowledge, $81 \%$ of the respondents answered with a significant yes. Networking belongs to an important channel of information and knowledge for their business.

The Networking basics question set is displayed in Table 2. Many of the respondents do not perceive networking as a one-time and coincidental action but as a systematic and longterm activity. In Table 2, there are answers, how the respondents characterise networking and how they would translate this expression into the Czech language. Many of the respondents use the word network, regularity, contacts, maintaining relationships, connecting, the social aspect. The respondents are aware of the types of networking, they mention online and offline networking activities and they also distinguish networking according to its goal - professional and interest networking, managed and coincidental networking, thematic networking.

The respondents know two or three companies or organisations from their inland, which focus on professional networking activities. Minimum of the respondents possesses knowledge of networking companies abroad. Except for two private companies, the respondents name generally chambers and societies, which primarily have the goal to connect interest groups. It was usually the entering to business, when the respondents heard most often about business networking and they realized that it is necessary to find a tool and mechanism for generating income and maintaining contacts, which are vital for a functional company. $94 \%$ of the respondents use networking to develop their careers or to find employees for their team. Systematic education in networking as a skill undergo $43 \%$ of the respondents and thus often as being a part of a business club, where education in the field of networking belongs to the customer service.

The question set Care of contact sphere of the given companies shows that $75 \%$ of the respondents have a strategy how to take care of existing contacts. Work time, which the owners of small and middle enterprises from my research dedicate to work with contacts is in the following ratio. $0 \%$ of time devote to work with contacts $6 \%$ of the respondents, up to $10 \%$ of the time $13 \%$ of the respondents, up to $20 \%$ of the time goes for $25 \%$ of the respondents, up to $30 \%$ of work time $25 \%$ of the respondents, up to $40 \%$ of the worktime $0 \%$ of the respondents, up to $50 \%$ of the time $19 \%$ of the respondents, over $50 \%$ of the time $12 \%$ of the respondents. The question of maintaining companies' contacts showed the following results. Contacts in paper form are found by $6 \%$ of the respondents, contacts in e-mail or phone book by $31 \%$, in a database by $19 \%$, and in a CRM system by $44 \%$ of the respondents. 
Table 2. Respondents' answers to networking.

\begin{tabular}{|c|c|}
\hline Description of the expression Networking & Translation of the expression Networking \\
\hline A targeted systematic building of relationships in business as well as non-business activities. & Building of contact networks. \\
\hline Making and maintaining contacts. & Contact networking. \\
\hline Creating network of contacts (relationships), connection, part of something, mutuality. & Building and supporting contacts, networking. \\
\hline Connecting people based on common interest. & Network. \\
\hline $\begin{array}{l}\text { Connecting people (companies) for the purposes of education and contacts and business, social events in case of } \\
\text { both. }\end{array}$ & Contact networking. \\
\hline A network of contacts, which can help each other reciprocally, a mutual connection of people. & Network of people, who work together. \\
\hline $\begin{array}{l}\text { Socialisation for the purposes of getting contacts and information and experience exchange, and business } \\
\text { development. }\end{array}$ & Networking. \\
\hline Creating relationships, where mutual enrichment and sharing happen. & Purposeful creating of relationships. \\
\hline Opportunity to obtain information, contacts, and inspiration. & $\begin{array}{l}\text { Spider's net, you catch intentionally and unintentionally } \\
\text { information, contacts, opportunities. }\end{array}$ \\
\hline A business club, regular meetings, collective training from companies. & Mutual education. \\
\hline A safety net for opportunities. & Connecting people among each other. \\
\hline $\begin{array}{l}\text { Purposeful creating of relationships with third parties, with the motivation and goal of receiving new contacts, } \\
\text { doing business or its arrangement or just cognition. }\end{array}$ & Establishing of relationships. \\
\hline Bonding people, establishing trust. Information-knowledge basis of creating. & Establishing of relationships \\
\hline It is using other people's contacts, creating a broad social tie. & Social ties. \\
\hline Establishing a contact portfolio and building relationships within the portfolio. & Camaraderie, I help you and you help me, make friends. \\
\hline $\begin{array}{l}\text { Regular meetings with value and depth with people who share interests or fields. Networking enables } \\
\text { meetings, sharing of information and contacts, education. }\end{array}$ & $\begin{array}{l}\text { Networking, joining networks and communities, which have a } \\
\text { common interest or goal. }\end{array}$ \\
\hline
\end{tabular}


Offline networking means for the respondents mostly a personal meeting, a form of live action, a business club, or a professional chamber. Online networking means for the respondents a form of a meeting or event via web platforms - ZOOM, Google Meet, Microsoft Teams, Go to Meeting, Hangout, Messenger, Skype. Again, a remarkably interesting trend occurs, at first, the respondents do not make a connection between on-line networking and social networks, they are aware of this fact only after an additional question, they mostly use Facebook, LinkedIn, Instagram, YouTube.

The applied measures have brought the following changes in using online and offline tools within networking, communication, and work with information and knowledge in the companies. All branches reduced the ratio of meetings in person and they use more often meetings via online platforms or telephone, e-mail. Even the respondents, who create craft activities reduced the personal visits by their customers. Some of the branches had to switch from $100 \%$ offline functioning to $100 \%$ online functioning. These companies had to adapt all their business processes and related information and knowledge transfers using IT technologies. The directly affected companies, where more than $80 \%$ of activities are impacted have a significant loss of clientele and associated turnover of the company. Those companies, which subject of business is not closed or restricted still have unchanged clientele and enough contracts and orders. $90 \%$ of the respondents will keep their business IT solutions even at the time, when they will be able to get back to meetings in person with their contact sphere. These are often in-house project management systems or consulting using online platforms, which will expand their existing range of products and services.

The question set Claims is displayed by the means of Figure 2. The claims regard the confirmed hypothesis within business networking activities and the discipline of Information and Knowledge Management.

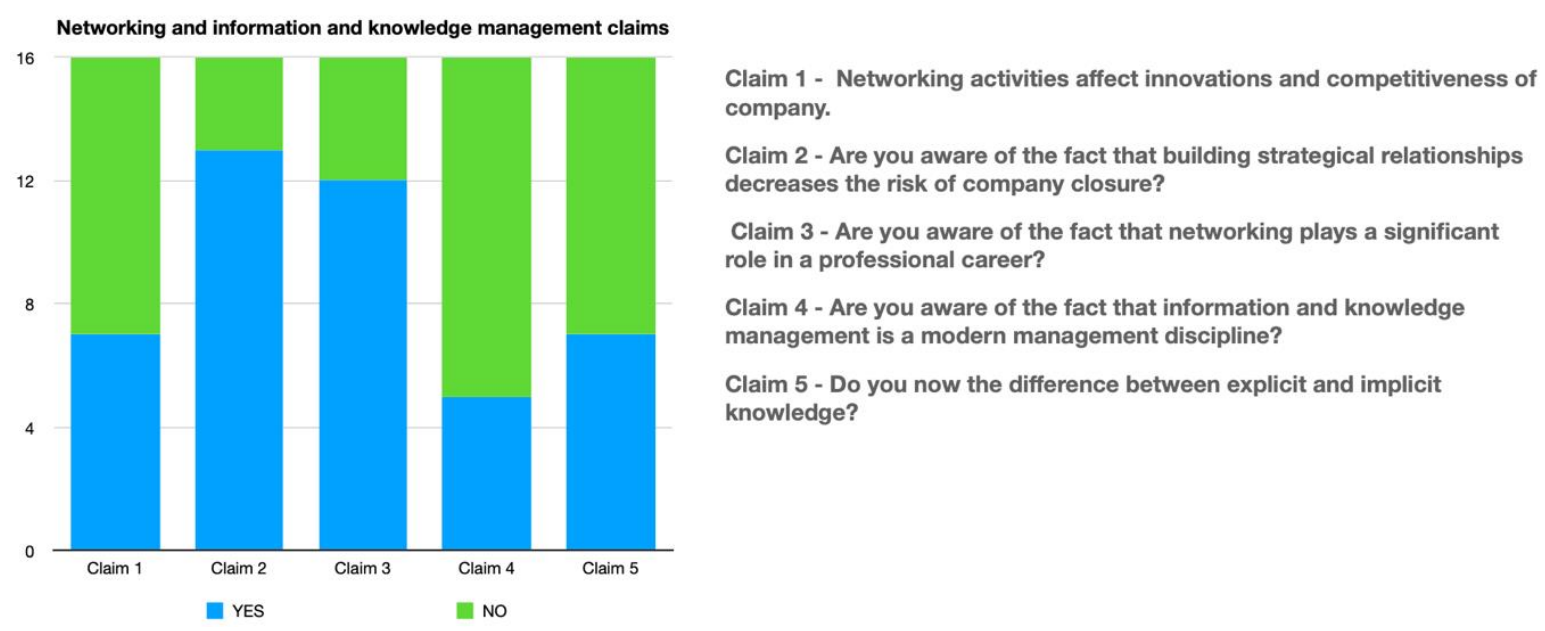

Figure 2. Networking and IZM claims.

\section{Discussion}

The strategy of using the networking tools and information and knowledge marketing tools in a management practice varies. The companies have different levels, which often correspond with their progress and development. The world-wide COVID-19 pandemic 
contributed to a massive transfer of business activities an also the networking activities with data transfer and processing, information and knowledge, their sharing and passing on within companies into the on-line world. Most of the business interactions have been transferred and adapted to the online environment. Nevertheless, most of the respondents from my research are not willing to meet new contacts in non-personal meetings, a handshake is crucial for the company owners in the sphere of business cooperation and trust, the parameter, on which each successful business activity stands. Naturally, it is possible to find exceptions, for example, e-shops, which do not need to build relationships in person with their customers, although it can be said that they are nearing them and personifying via social networks. Modern technologies keep developing and shifting the limits; therefore, it is not out of the question that people may adapt to this sudden change in a greater measure. Owing to the pandemic development, the old habits of business activities will probably not return. Many companies and industries closed or will close due to this change and on the contrary, new sectors and industries will develop. An interesting consideration is, how will the future look like in other industries, which were not directly closed or restricted. It is possible to consider that the demand in some of the industries will decrease with a delay thanks to the connected and open economy, which prevails in the world nowadays. The deciding factor will be the households' behaviour and their consumption and willingness to treat themselves to other products and services above the basic needs.

\section{Conclusions}

The qualitative research in the form of interviews was very extensive. The respondents stated many interesting observations. I succeeded in collecting a high volume of data, which is possible to use for my further research. The tools, which are being used within existing contacts are considered the greatest advantage within the changes due to the COVID-19 pandemic as seen by the respondents. Saving time and transfer costs and meeting one another through web conferencing are evaluated by all the respondents as a positive change. When acquiring new contacts (most often clients), they do not consider online tools to be of high quality and do not want to follow the online path, except for the above-mentioned e-shop.

The fundamental finding of my research is the reciprocity of networking as a marketing management discipline, and information and knowledge management. The research proved networking to be a tool of information and knowledge management, as it is a channel for sharing and transfer of information, knowledge, education, and brings an innovation potential, and enhances the competitiveness of an individual as well as a company or organisation. Information and knowledge management is simultaneously considered a

networking tool. Awareness of the infrastructure, system, processes, hierarchy of expressions, search, understanding, and distribution of knowledge contributes to the improvement of transmissions in the network and thus increases its overall value and benefits to individual players.

Acknowledgments: The work was supported by the internal project "SPEV - Economic Impacts under the Industry 4.0 / Society 5.0 Concept", 2021, University of Hradec Králové, Faculty of Informatics and Management, Czech Republic. 


\section{References}

Bureš, V. (2007). Znalostní management a proces jeho zavádění: průvodce pro praxi. Grada, Management v informační společnosti.

Faroque, A. R., Morrish, S. C., \& Ferdous, A. S. (2017). Networking, business process innovativeness and export performance: the case of South Asian low-tech industry. Journal of Business $\mathcal{E}$ Industrial Marketing. 32(6), 864-875. https://doi.org/10.1108/JBIM-06-2015-0113

Ford, D., \& Mouzas, S. (2013). The theory and practice of business networking. Industrial Marketing Management, 42(3), 433-442. https://doi.org/10.1016/j.indmarman.2013.02.012

Hardwick, J., Cruickshank, D., \& Anderson, A. R. (2012). Innovation in small business: comparing face-to-face with virtual networking. Journal of Business Strategy, 33(5), 51-58. https://doi.org/10.1108/02756661211282795

Henneberg, S. C., Naudé, P., \& Mouzas, S. (2010). Sense-making and management in business networks-Some observations, considerations, and a research agenda. Industrial Marketing Management, 39(3), 355-360. https://doi.org/10.1016/j.indmarman.2009.03.011

Ivanova-Gongne, M., \& Torkkeli, L. (2018). No manager is an island: culture in sensemaking of business networking. Journal of Business \& Industrial Marketing, 33(5), 638-650. https://doi.org/10.1108/jbim-07-20160154

Kubberød, E., Viciunaite, V., \& Fosstenløkken, S. M. (2019). The role of effectual networking in small business marketing. Journal of small business and enterprise development, 26, 747-763. https://doi.org/10.1108/JSBED-062019-0199

Petrash, G. (1996). Dow's journey to a knowledge value management culture. European management journal, 14(4), 365-373. https://doi.org/10.1016/0263-2373(96)00023-0

Prisma transparent reporting. (2021, January 21) http://www.prisma-statement.org

Schoonjans, B., Van Cauwenberge, P., \& Vander Bauwhede, H. (2013). Formal business networking and SME growth. Small Business Economics, 41(1), 169-181. https://doi.org/10.1007/s11187-011-9408-6

Sunassee, N. N., \& Sewry, D. A. (2002). A theoretical framework for knowledge management implementation. In Proceedings of the 2002 annual research conference of the South African institute of computer scientists and information technologists on Enablement through technology (pp. 235-245).

Tallinn University. (2021). Development of Information and Knowledge Management. https://www.tlu.ee/ sirvir/Information\%20and\%20Knowledge\%20Management/Development\%20of\%20IK M/development_of_knowledge_management_2.html

ZOOM. (2021, January 21) https://zoom.us 